\title{
Three-component solids velocity measurements in the middle section of a riser
}

\author{
M.N. Pantzali, N. Lozano Bayón, G.J. Heynderickx*, G.B. Marin \\ Ghent University, Faculty of Engineering and Architecture, Laboratory for Chemical \\ Technology, Krijgslaan 281 S5, B-9000 Gent, Belgium \\ *tel. +32 (0)9 26445 32, e-mail: Geraldine.Heynderickx@ugent.be; fax: +32 (0)9 2644999
}

\begin{abstract}
Coincident three-component experiments are conducted in a 8.7-m-high cylindrical riser (internal diameter $0.10 \mathrm{~m}$ ) of a Pilot-Scale Cold-Flow Circulating Fluidized Bed set-up using two LDA probes. At heights close to the solids inlet, the flow is highly disturbed due to the asymmetrical position of both the air and solids inlets. A fully developed parabolic axial solids velocity field is observed at a height of $2.5 \mathrm{~m}$. The radial and azimuthal solids velocity components are significantly smaller than the axial one and are close to zero. The velocity fluctuations in the flow direction are larger than in the other directions, showing that the flow is anisotropic. However, the radial and azimuthal velocity fluctuations are higher than the corresponding mean velocities. All fluctuating velocities are decreasing significantly with increasing riser height, i.e. as the flow becomes more developed. No average down-flow of solids is recorded, not even close to the wall, probably due to the very high dilution $\left(\varepsilon_{\mathrm{s}}<0.2 \%\right)$ used in the presented work. The measured turbulent kinetic energy indicates that the flow is dominated by wall-particle rather than intra-particle collisions. The acquired data can be useful for validation of riser simulations.
\end{abstract}

\section{INTRODUCTION}

The gas-solid flow structures in a riser affect the heat, mass and momentum transfer in the riser reactor, and the residence time of the phases in the riser. The latter influences the contact times between the phases and, thus, the conversion of the feed and the product yields that is the overall performance of the reactor. Several efforts to model the flow structures in a riser have been made. However, the numerical complexity and the enormous computational load requires the introduction of significant modeling simplifications [1]. At present, most of the CFD riser simulations remain limited to calculating the flow in a simplified 2-D riser domain, making it impossible to reconstruct the $3 \mathrm{D}$ nature of the flow in the riser. In view of the importance of flow structures, the simplified approach does not allow to determine the real mechanisms underlying the complex state of motion [2]. As a consequence, hydrodynamic modeling of a riser has not yet been entirely successful [1].

Due to the complexity of the gas-solid flow, accurate experimental measurements of the riser flow are difficult to obtain. The development of theoretical models and empirical equations to simulate the riser flow suffer from this lack of relevant experimental data, e.g. in view of model validation and refinement [3-4]. Furthermore, the majority of the available experimental data for two-phase riser flow provides at its best two simultaneously measured solids velocity components. Two-dimensional experimental data are insufficient to validate and refine existing or develop new accurate computational flow models for an in nature 3-D flow [3]. Therefore, precise experimental data providing coincident measurements of the three 
components of the solids velocity vectors are needed to gain insight into the 3-D flow characteristics along the entire riser height.

Laser Doppler Anemometry (LDA) [5-9] is widely used for studying the gas-solid flow in transparent risers. Mostly coincident measurements of two components of the solids velocity are reported. An optical measuring technique like LDA can be used for very dilute particle flows only, as for higher volume fractions, mostly encountered in CFBs, the flow becomes opaque. Nevertheless, the study of riser flows more dilute than the industrial ones, remains interesting in order to understand the fundamental mechanisms that prevail in gas-solid flow. The simulation models applied for dilute flow can be verified and improved. Next, these models can be extended for more complex dense flows, where the interaction between gas turbulence on the one hand and particle fluctuations on the other hand becomes significant [10]. Thus, with the non-intrusive LDA measuring technique, providing accurate threecomponent solids velocity fields in dilute riser flow, valuable data can be obtained in view of better modeling. In the presented work, the solids flow in the middle section of a pilot riser set-up is studied experimentally. The solids enter the riser through a one-side solids inlet configuration, implying that a three-dimensional flow field is created. Extensive coincident measurements of the three components of the solids velocity field in the middle section of the riser, still difficult to find in the riser related literature, have been acquired using a two-probe LDA.

\section{EXPERIMENTAL SET-UP AND CONDITIONS}

The CFB pilot set-up mainly consists of an $8.7 \mathrm{~m}$ long and $0.1 \mathrm{~m}$ diameter Pyrex glass cylindrical riser, two glass cyclones, a fluidized bed storage tank for the particles, a $2 \mathrm{~m}$ long and $0.08 \mathrm{~m}$ diameter standpipe/solids inlet line and a mechanical iris valve to regulate the solids flow into the riser. A detailed description has been given in previous publications [9, 11-12]. The riser is operated in 'cold flow', that is only non-reactive particle flow patterns are measured. The solids used are FCC-E catalyst particles with a density of $1550 \mathrm{~kg} / \mathrm{m}^{3}$ and a Sauter mean diameter of $77 \mu \mathrm{m}$, classified as Geldart Group A particles [13]. The gas phase, air, enters the riser via the bottom through a $0.05 \mathrm{~m}$ diameter line. This inlet line expands to the riser diameter at $0.3 \mathrm{~m}$ above ground level (Figure 1$)$. The origin $(0,0,0)$ of the coordinate axes used, corresponds to the center point of this expansion ring. The riser operates at atmospheric conditions. Experimental volumetric flow rates of 100 and $150 \mathrm{Nm}^{3} / \mathrm{h}$ in the air inlet line are used, corresponding to 3.5 and $5.3 \mathrm{~m} / \mathrm{s}$ of superficial air velocity in the riser, respectively. The solids flux rate in the riser is constant at $10 \mathrm{~kg} / \mathrm{m}^{2} \mathrm{~s}$, meaning that the mean solids volume fraction, $\varepsilon_{\mathrm{s}}$, is for all cases less than $0.2 \%$. The air inlet tube is parallel to the X-axis. The solids enter the riser through a single side inlet situated in the YZ-plane and inclined $35^{\circ}$ clockwise as compared to the Z-axis. The

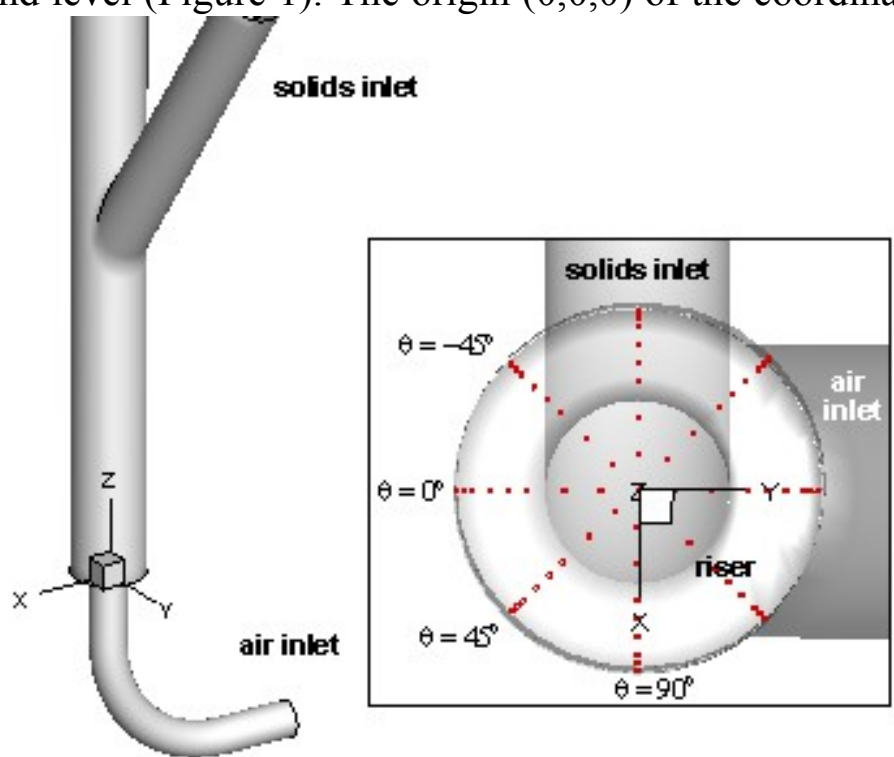

Figure 1: Riser inlet section and detail of the riser XY cross section with the measuring planes. 
intersection of the riser and the solids inlet tube is positioned at a height of 0.47 to $0.63 \mathrm{~m}$ above the axes origin. In the presented study, a blinded T-outlet with a $0.1 \mathrm{~m}$ diameter and a $0.34 \mathrm{~m}$ extension height, positioned $51^{\circ}$ counter-clockwise as compared to the solids inlet, is used.

The system is equipped with a two-probe Laser Doppler Anemometry (LDA) set-up, that allows to perform coincident three-component solids velocity measurements in the gas-solids flow. A water-cooled class IV Argon-Ion laser (Stabilite 2017, Spectra Physics ${ }^{\circledR}$ ) is used as light source. Two FiberFlow backscatter probes (60 mm diameter, DANTEC) transmit a pair of 'green' and a pair of 'blue' laser beams (2D probe) and a pair of 'violet' laser beams (1D probe). The probes are positioned in a XY plane with a $90^{\circ}$ angle in between. The three velocity components of a single particle passing through the LDA measuring volume are measured simultaneously. This is referred to as performing coincident measurements. The latter requires the two probes to be aligned very accurately. The probes are fixed on a traverse manifold that enables to alter the relative position of the two probes as well as to reposition stepwise and accurately the whole measuring volume relatively to the riser. The LDA with the traverse manifold is placed inside the cabin of an elevator, which allows to position the LDA at any desired riser height. At each riser height, measurements are performed along four radial planes marked with $\theta$-angles (Figure 1). In the presented study experimental data are gathered at riser heights between $0.86 \mathrm{~m}$ and $5.5 \mathrm{~m}$.

\section{STATISTICAL PROCESSING}

The mean transformed solids velocity in the k-direction, $\mathrm{U}_{\mathrm{k}}$, is calculated following Eq. 1 using a weighting factor, $\eta_{\mathrm{i}}$ (Eq. 2), to eliminate velocity bias [14].

$$
\begin{gathered}
U_{k}=\eta_{i} \sum_{i=1} v_{k, i} \\
\mathrm{I}_{\mathrm{i}}-\frac{\overline{1}}{\sum_{\mathrm{j}=0}^{\mathrm{N}-1} \mathbf{t}_{\mathrm{j}}}
\end{gathered}
$$

In Eq. $1 \mathbf{v}_{\mathrm{k}, \mathrm{i}}$ is the instantaneous velocity component in the k-direction and $\mathrm{N}$ is the number of sampled solid particles per measuring position. The standard deviation of the velocity in the $\mathrm{k}$ $\mathbf{U}_{\mathbf{k}}^{\prime}$

direction, , is calculated using Eq. 3. $\mathrm{N}$ must be taken large enough to avoid high statistical uncertainty. In the presented study, the criteria selected for ending the data collection at a given measuring position are either 10,000 sampled solid particles or 3 minutes of sample acquisition time. The $95 \%$ confidence intervals for the gathered data are determined using Eq. 4. The confidence interval is an indication of the reliability of the measured particle velocities [14].

$$
\begin{gathered}
U_{k}^{\prime}=\sqrt{\sum_{i=1} \eta_{i}\left(v_{k, i}-U_{k}\right)^{2}} \\
v_{k, 95 \mathbf{x}}= \pm 1.96 \sqrt{\frac{U_{k}^{2}}{N}}
\end{gathered}
$$




\section{RESULTS AND DISCUSSION}

Visual observations show that the solids enter the riser at a height of about $0.5 \mathrm{~m}$, through the side solids inlet with a negative (downwards) axial velocity component due to the tube inclination and gravity. The ascending air decelerates and reverses the downward flow of the particles, creating a jet-like flow close to the solids inlet. As a result, the particles concentration is locally high. This flow pattern results in a gas flow, by-passing the solids, that is the gas preferentially flows in a streaming jet along one side of the riser. Next, the solids are gradually dispersed by the air with increasing riser height.

In Figure 2 the evolution of the solids velocity fields for the two air flow rates along the riser height is presented. The trend is found to be similar for all $\theta$ planes studied. In Figure 2, the results for the $0^{\circ}$ and the $90^{\circ}$ plane are presented. At all measured riser heights higher values at the center of the riser and lower at the riser walls are recorded. The axial velocity field is not observed to be flat at the riser center; a rather parabolic-shape field is recorded. This velocity field shape agrees with the work of Van engelandt et al. [9] for the middle section of the riser. At $Z=0.86 \mathrm{~m}$, still close to the solids inlet, the axial velocities magnitudes are not symmetrical with respect to the riser center. The latter is most probably due to the solids jet and the gas by-passing this jet, as discussed above. This phenomenon is observed in all $\theta$ planes, indicating that the flow is highly disturbed at the riser height of $0.86 \mathrm{~m}$ due to the asymmetrical position of the air and solids inlets. With increasing riser height, the axial solids velocities increase slightly and the flow gets more developed. The axial solids velocity components do not change significantly for riser heights above $2.5 \mathrm{~m}$. The effect of the riser outlet is not detected at the riser height of $5.5 \mathrm{~m}$, the maximum height studied. The maximum solids axial velocity at the highest measuring positions is close to the respective superficial gas velocity.

As expected, the radial and azimuthal solids velocity magnitudes are significantly lower than the axial ones. The azimuthal components exhibit higher mean values at the walls and lower at the riser center. This effect tends to damp out with increasing riser height, where the azimuthal components tend to become zero. The radial components are almost zero close to the riser walls and have slightly higher mean values in the riser center. As the riser height increases, the radial and azimuthal solids velocity magnitudes become smaller, indicating that the entrance section effects are damped out and the flow indeed becomes gradually developed. Moving away from the inlet section, the solids velocity field tends to become symmetrical with respect to the riser center. An observation worth mentioning is that for the riser heights studied, no average down-flow of solids has been recorded, not even along the riser wall, probably due to the dilute flow. This has been also mentioned by other researchers studying dilute riser flow [15]. It could possibly also imply that outlet effects are not yet felt here, but this has to be further studied. Furthermore, for single particles negative axial instantaneous velocities are occasionally recorded, but the mean axial velocities remain positive. The presence of reverse flow, mainly a wall effect, is typical for core-annulus flows [1]. Hence the lack of it might be an indication that core-annulus flow is not observed in the presented work due to the dilute flow $\left(\varepsilon_{\mathrm{s}}<0.2 \%\right)$.

Figure 3 shows typical axial, radial and azimuthal root mean square (RMS) solids velocities in two different riser planes $\left(+45^{\circ}\right.$ and $\left.-45^{\circ}\right)$ and for the two air flow rates studied. The RMS velocities are a measure of the particle velocity fluctuations, an important mixing property [9]. It is seen that the highest values of velocity fluctuations (axial, azimuthal and radial) are recorded close to the solids inlet, $(Z=0.86 \mathrm{~m}$ and $Z=1.5 \mathrm{~m})$, where the solids velocities are still significantly affected by the solids inlet and the jet-like flow formed next to it. For the same operating conditions, the RMS-velocities in the axial direction are significantly higher than the radial and azimuthal values, which are of the same order of magnitude. Larger velocity 
fluctuations in one direction correspond to an anisotropic flow. This is to be expected as the turbulence in riser flows is proved to be anisotropic [3]. The anisotropy could be attributed to the length to diameter ratio of the riser that is much larger than unity, implying that the axial
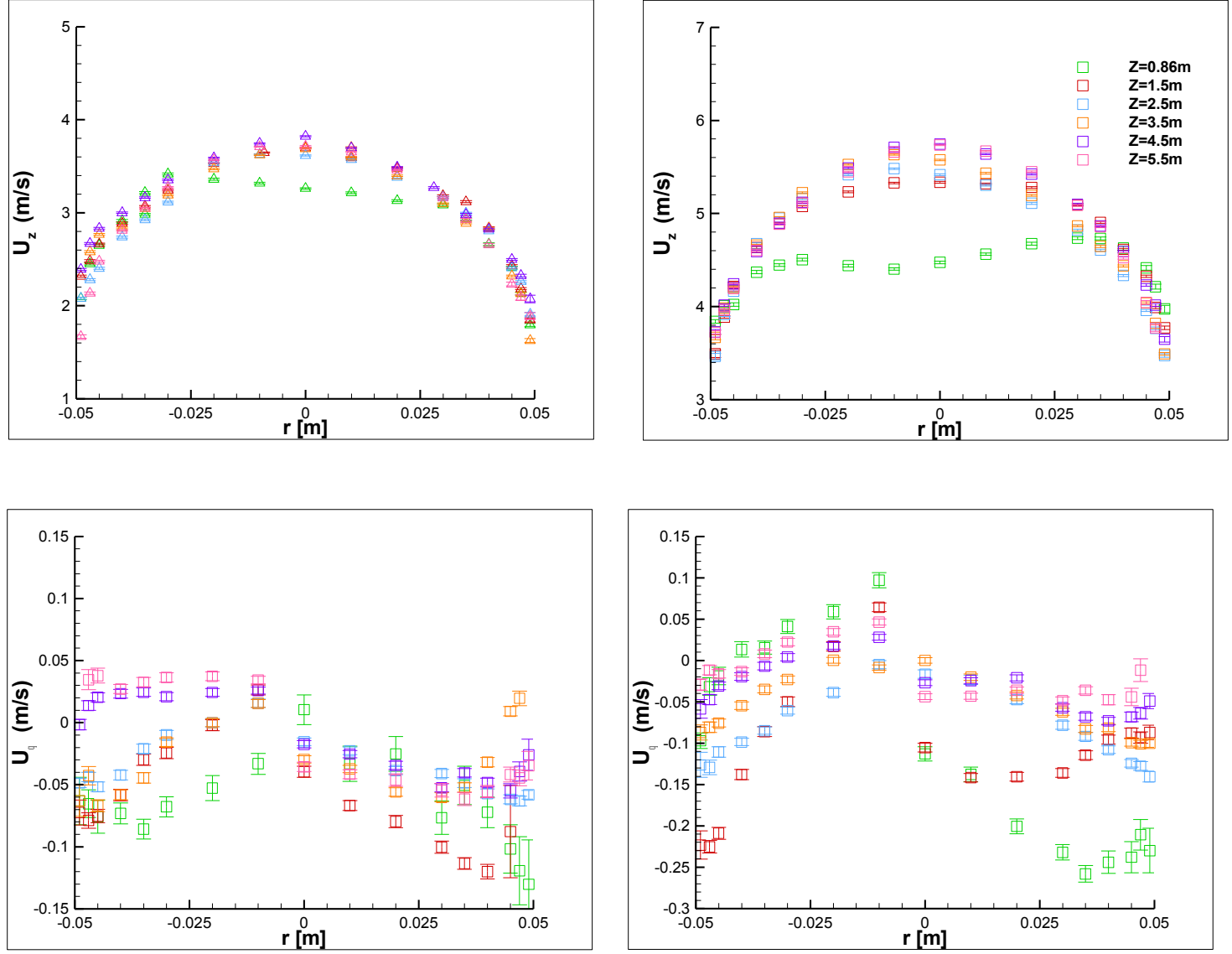

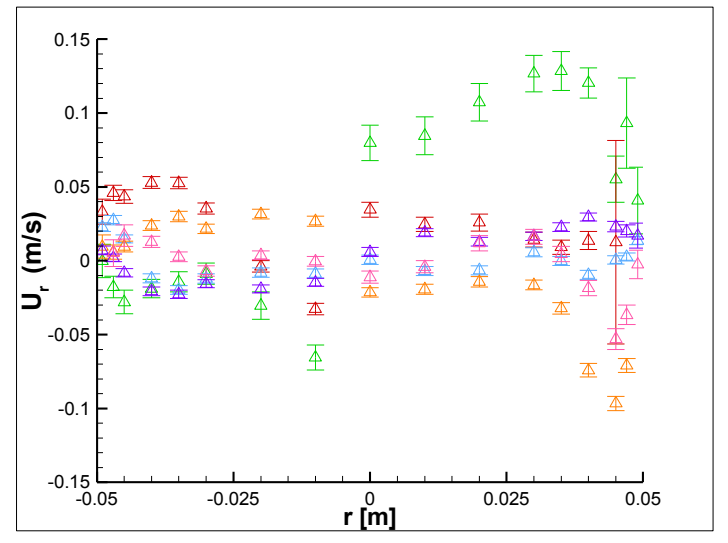

a)

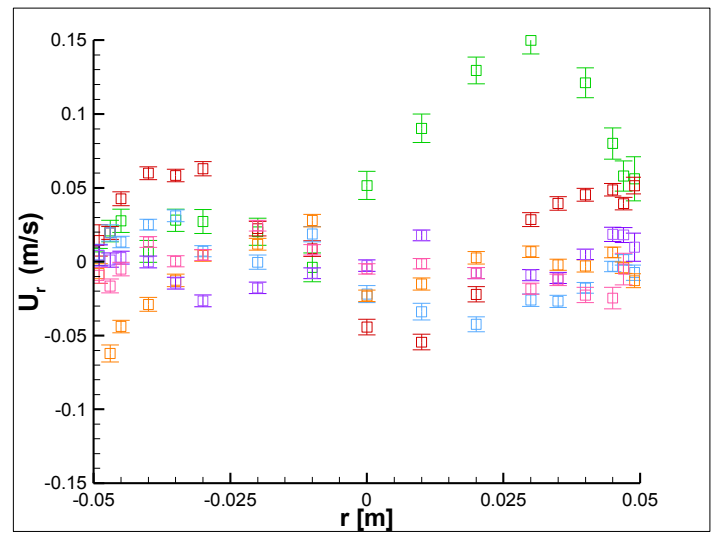

b)

Figure 2: Mean solids velocities for a) position $\theta=0^{\circ}$ and air flow rate $100 \mathrm{Nm}^{3} / \mathrm{h}$ and b) position $\theta=+90^{\circ}$ and air flow rate $150 \mathrm{Nm}^{3} / \mathrm{h}$. Positive azimuthal velocity is in the counter-clockwise direction, positive radial velocity is pointing away from the center and the error bars show the $95 \%$ confidence intervals.

and radial flow is strongly affected by the presence of the walls. Compared to the mean axial velocities, $\mathrm{U}_{z}$, however, the axial velocity fluctuations are of a lower order of magnitude, while the radial and azimuthal solid velocity fluctuations are significantly higher than the corresponding mean solid velocities. This is in agreement with previous solids velocity 
measurements in riser flows [3-4, 8]. This observation implies that the instantaneous radial and azimuthal particle velocities exhibit a rather broad distribution of slightly positive and slightly negative values, which result in very low mean values upon averaging. In general, the three RMS velocity components tend to decrease with increasing riser height for both air flow rates, indicating that the largest fluctuations are located at the solids inlet and that the flow is being gradually developed.
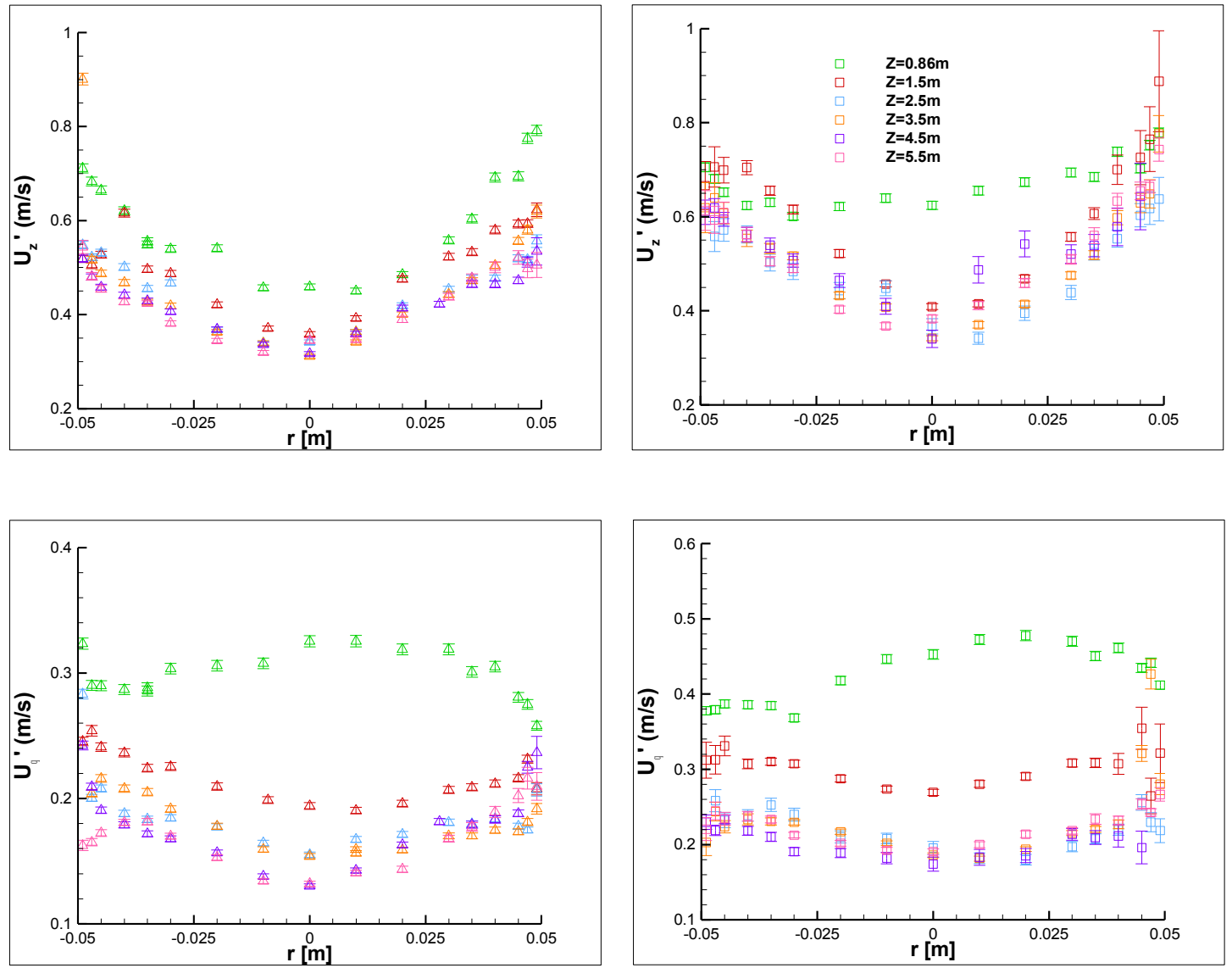

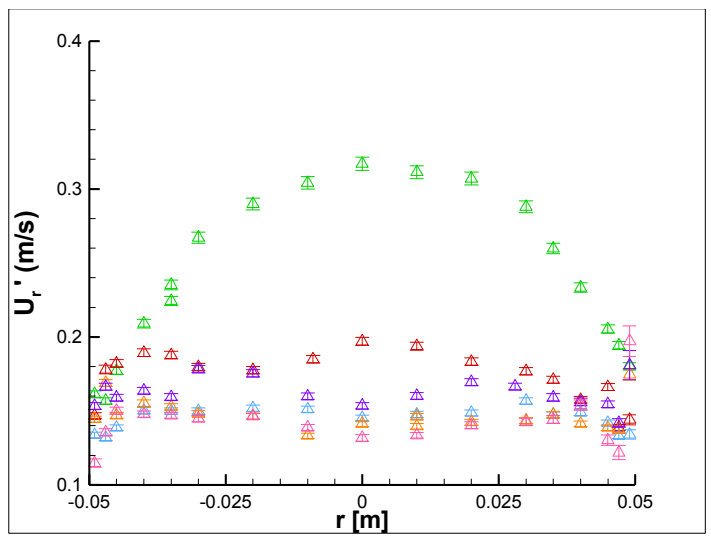

a)

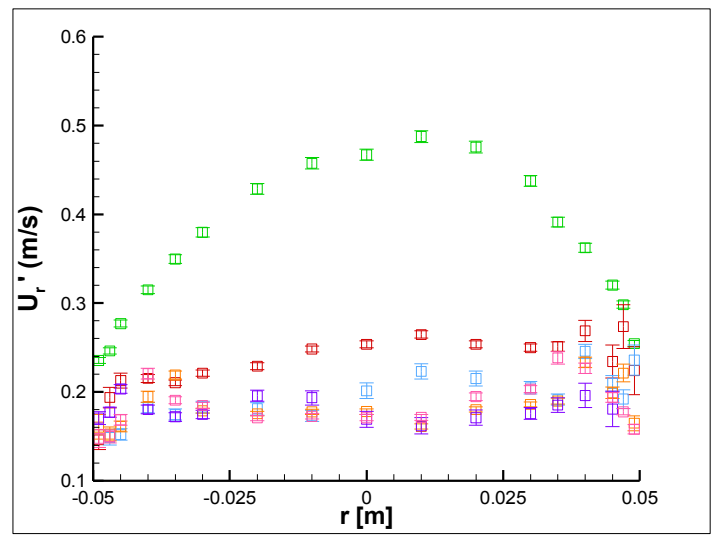

b)

Figure 3: RMS solids velocities for a) position $\theta=+45^{\circ}$ and air flow rate $100 \mathrm{Nm}^{3} / \mathrm{h}$ and b) position $\theta=-45^{\circ}$ and air flow rate $150 \mathrm{Nm}^{3} / \mathrm{h}$. The error bars represent the $95 \%$ confidence intervals.

The general trend for the axial, $\mathbf{U}_{\mathbf{z}}^{\prime}$, and azimuthal, $\mathbf{U}_{\boldsymbol{\theta}}^{\prime}$, RMS velocities is an increasing value when approaching the riser walls and lower values close to the riser center. However, the 
radial RMS velocities, $\mathbf{U}_{\mathbf{r}}^{\prime}$, have an almost constant value along the riser diameter, with slightly lower values near the riser walls. As a result, the particle-wall collisions will mostly affect the axial and azimuthal velocities rather than the radial velocity.

Figure 2 confirms that increasing the air flow rate results in increasing axial, radial and azimuthal particle mean velocities. Furthermore, a higher superficial gas velocity results in higher solids velocity fluctuations (Figure 3). For the presented work with air flow rates of $100 \mathrm{Nm}^{3} / \mathrm{h}$ and $150 \mathrm{Nm}^{3} / \mathrm{h}$ this increase is approximately $25 \%$ in radial and azimuthal direction, in contrast to the axial direction with a more modest increase of about $15 \%$. This difference is probably related to the way the RMS velocities are calculated (Eq. 3). Since the mean radial and azimuthal velocities are close to zero, a small increase of the instantaneous values will affect the RMS values more. However, the values remain of the same order of magnitude for both air flow rates. This observation is in agreement with Van den Moortel et al. [8], who also studied a dilute riser flow. However, Bhusarapu et al. [3] observe the opposite behavior, when comparing the Dilute Phase Transport and the Fast Fluidization regimes. In the latter work, it is noted that under dilute flow conditions, two competing mechanisms affect the observed fluctuations. On the one hand, increasing the solids concentration, thereby decreasing the mean free path of the solids, results in the reduction of the solids fluctuations. On the other hand, an increased solids hold-up, resulting in a higher particle collision frequency, increases the velocity fluctuations. In the presented study, the former mechanism prevails, as the flow is very dilute and the inter-particle collisions do not significantly affect the flow. When the air flow rate is increased, the solids volume fraction is reduced as the solids flow rate remains constant. As a result, the increased mean free path of the particles enables more intense solids fluctuations.

Figure 4 shows the radial distributions of the computed turbulent kinetic energy (Eq. 5) at the six riser heights studied, in the $0^{\circ}$ plane. The turbulent kinetic energy is higher for the more dilute flow $\left(150 \mathrm{Nm}^{3} / \mathrm{h}\right.$ air flow rate) than for the denser flow $\left(100 \mathrm{Nm}^{3} / \mathrm{h}\right.$ air flow rate), due to the increased mean free path between particles as explained above. Furthermore, for both gas flow rates studied and for all heights, the turbulent kinetic energy is lower at the riser center and higher close to the walls, indicating that most probably the flow is dominated by wall-particle rather than intra-particle collisions. This trend is contrary to the findings of Bhusarapu et al. [3] and is probably related to the dilute riser flow studied. The turbulent kinetic energy decreases with increasing riser height, showing that the flow is developing.

$$
k_{s}=\frac{1}{2}\left(U_{z}^{\prime 2}+U_{\theta}^{\prime 2}+U_{r}^{\prime 2}\right)
$$

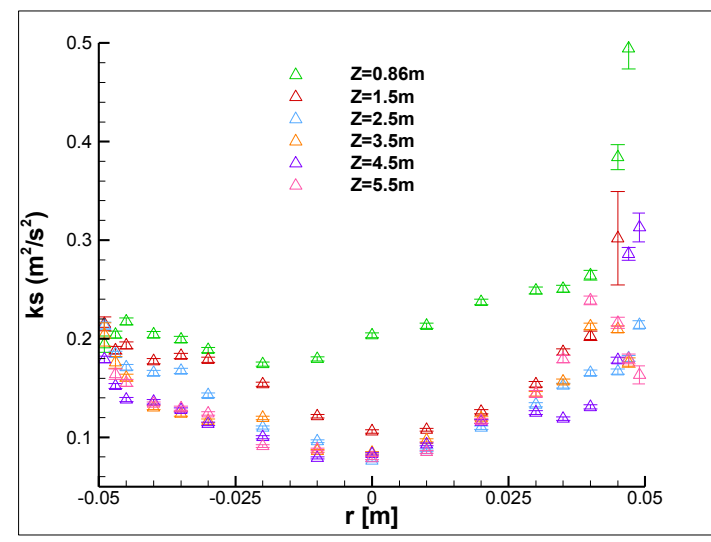

a)

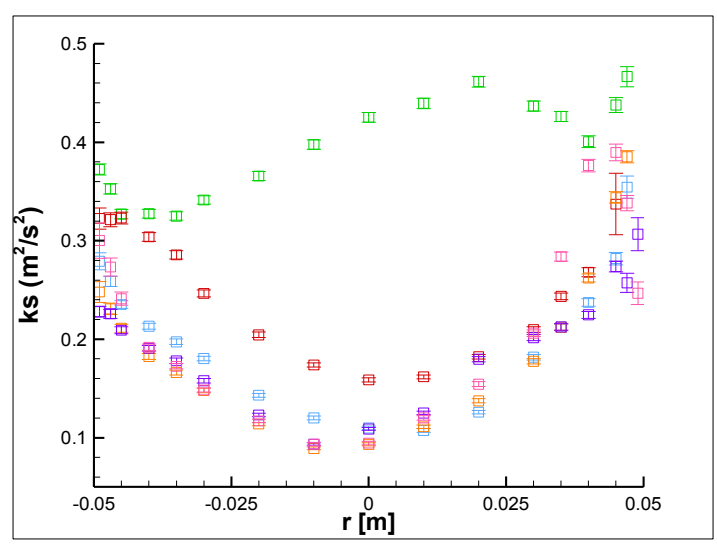

b)

Figure 4: Turbulent kinetic energy for position $\theta=0^{\circ}$ and air flow rate a) $100 \mathrm{Nm}^{3} / \mathrm{h}$ and b) $150 \mathrm{Nm}^{3} / \mathrm{h}$. 
The error bars represent the 95\% confidence intervals.

\section{CONCLUSIONS}

An experimental study of the solids velocity field in a Circulating Fluidized Bed cold-flow riser set-up is performed using a two-probe LDA with the aim of studying the hydrodynamics of gas-solid two-phase flow in risers. The three component solids velocity data in dilute riser flow are needed to fully understand the flow development in a riser. Furthermore, they are useful for validation of 3D computational results for the riser. Experiments are carried out at pilot-riser heights between 0.86 and $5.5 \mathrm{~m}$ in four radial positions and for two air flow rates. The solids velocity field development under different operating conditions is studied. Fully developed fields are observed above $2.5 \mathrm{~m}$ of riser height. The maximum particle velocity is always measured in the center of the riser. Under conditions of fully developed flow the maximum solid particle velocity values in the center of the riser are observed to come close to the superficial gas velocity in the riser. Negative mean axial solids velocities are not recorded under the studied operating conditions, because the flow is dilute $\left(\varepsilon_{s}<0.2 \%\right)$. The axial solids velocity components are observed to fluctuate more intensely than the radial and azimuthal components. For the latter components, however, the fluctuating velocities dominate the flow; their value is usually higher than the respective mean solids velocity components. The kinetic turbulent energy is also estimated based on the experimental data and the results indicate that the flow is dominated by wall-particle rather than intra-particle collisions. In all cases, the fluctuations and the turbulent kinetic energy decrease with increasing riser height, indicating that the velocity field is being gradually developed.

\section{LITERATURE}

[1] Berruti F., Pugsley T.S., Godfroy L., Chaouki J. and Patience G.S., Canadian Journal of Chemical Engineering 1995;73:579.

[2] Wang W., Lu B., Zhang N., Shi Z. and Li J., International Journal of Multiphase Flow 2010;36:109.

[3] Bhusarapu S., Al-Dahhan M.H. and Dudukovic M.P., Powder Technology 2006;163:98.

[4] Godfroy L., Larachi F. and Chaouki J., Canadian Journal of Chemical Engineering 1999;77:253.

[5] Ibsen C.H., Solberg T., Hjertager B.H. and Johnsson F., Experimental Thermal and Fluid Science 2002;26:851.

[6] Mathiesen V., Solberg T., Arastoopour H. and Hjertager B.H., AIChE Journal 1999;45:2503.

[7] Mathiesen V., Solberg T. and Hjertager B.H., International Journal of Multiphase Flow 2000;26:387.

[8] Van den Moortel T., Azario E., Santini R. and Tadrist L., Chemical Engineering Science 1998;53:1883.

[9] Van engelandt G., De Wilde J., Heynderickx G.J. and Marin G.B., Chemical Engineering Science 2007;62:339.

[10] Benyahia S., Arastoopour H., Knowlton T.M. and Massah H., Powder Technology 2000;112:24.

[11] De Wilde J., Van engelandt G., Heynderickx G.J. and Marin G.B., Powder Technology 2005;151:96. 
[12] Van engelandt G., Heynderickx G.J., De Wilde J. and Marin G.B., Chemical Engineering Science 2011;66:5024.

[13] Geldart D., Powder Technology 1973;7:285.

[14] BSA Flow Software v.2.1, Installation and User's Guide. In $8^{\text {th }}$ ed.; Dantec Corporation: Skovlunde, Denmark, 2003.

[15] Zhang Y.-F. and Arastoopour H., Powder Technology 1995;84:221. 